\title{
A Closure Study of Aerosol Optical Properties at a Regional Background Mountainous Site in Eastern China
}

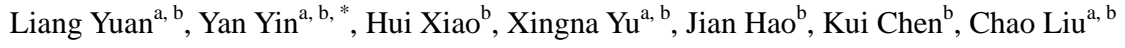 \\ ${ }^{a}$ Collaborative Innovation Center on Forecast and Evaluation of Meteorological Disasters, Nanjing University of \\ Information Science \& Technology, Nanjing 210044, China \\ ${ }^{b}$ Key Laboratory for Aerosol-Cloud-Precipitation of China Meteorological Administration, School of Atmospheric \\ Physics, Nanjing University of Information Science and Technology, Nanjing 210044, China
}

\begin{abstract}
There is a large uncertainty in evaluating the radiative forcing from aerosol-radiation and aerosol-cloud interactions due to the limited knowledge on aerosol properties. In-situ measurements of aerosol physical and chemical properties were carried out in 2012 at Mt. Huang (the Yellow Mountain), a continental background mountainous site in eastern China. An aerosol optical closure study was performed to verify the model outputs by using the measured aerosol optical properties, in which a spherical Mie model with assumptions of external and core-shell mixtures on the basis of a two-component optical aerosol model and high size-segregated element carbon (EC) ratio was applied. Although the spherical Mie model would underestimate the real scattering with increasing particle diameters, excellent agreement between the calculated and measured values was achieved with correlation coefficients above 0.98 . Sensitivity experiments showed that the EC ratio had a negligible effect on the calculated scattering coefficient, but largely influenced the calculated absorption coefficient. The high size-segregated EC ratio averaged over the study period in the closure was enough to reconstruct the aerosol absorption coefficient in the Mie model, indicating EC size resolution was more important than time resolution in retrieving the absorption coefficient in the model. The uncertainties of calculated scattering and absorption coefficients due to the uncertainties of measurements and model assumptions yielded by a Monte
\end{abstract}


Carlo simulation were $\pm 6 \%$ and $\pm 14 \%$ for external mixture and $\pm 9 \%$ and $\pm 31 \%$ for core-shell mixture, respectively. This study provided an insight into the inherent relationship between aerosol optical properties and physicochemical characteristics in eastern China, which could supplement the database of aerosol optical properties for background sites in eastern China and provide a method for regions with similar climate.

Keywords: aerosol optical properties; closure study; uncertainty; size-segregated; mixing state; Mt. Huang

*Corresponding Author: Yan Yin (yinyan@ nuist.edu.cn)

Address: School of Atmospheric Physics, Nanjing University of Information Science and Technology, Ningliu Road 219, Nanjing, China; Tel/Fax: +86-25-58731207

\section{Introduction}

Atmospheric aerosol particles can affect the Earth's energy balance and climate by aerosol-radiation interactions through scattering and absorbing the incident solar radiation (Charlson et al., 1992) and by aerosol-cloud interactions by acting as cloud condensation nuclei $(\mathrm{CCN})$ and ice nuclei (IN) in cloud formation to modify the optical properties and life time of clouds (Andreae and Rosenfeld, 2008). Recently, it has also been found that the influences of atmospheric aerosol particles on solar radiation have an important impact on the variations of crop evapotranspiration (Valipour, 2014; 2015a; 2015b), which plays a vital role in water management with respect to global water crisis issues (Valipour, 2015c; 2015d). Light-absorbing carbon (LAC), one of the most important components of atmospheric aerosols, which dominates the light absorption in the atmosphere (Moffet and Prather, 2009) and hence has a positive radiative forcing on the climate system (Jacobson, 2001), is one of the largest uncertainties in quantifying the global 
radiative forcing of aerosols.

LAC is an individual aggregate and unmixed once it is emitted into the atmosphere, where it tends to mix with other chemical components during air mass aging (Riemer et al., 2004). Previous model studies have estimated that the direct radiative forcing of LAC at the top of the atmosphere ranged widely from +0.17 to $+0.80 \mathrm{~W} / \mathrm{m}^{2}$ with the evolution of its mixing state (Jacobson, 2000; Chung and Seinfeld, 2002). Jacobson (2000) showed that the positive radiative forcing of LAC for the internal mixture was approximately 3 times higher than that for the external one. However, recent research showed that the light absorption of LAC was less than that predicted from observationally constrained theoretical calculations, which indicated that many climate models might overestimate warming by LAC ( Cappa et al., 2012). This is due not only to the highly uneven horizontal, vertical, and temporal distributions of aerosols (IPCC, 2013) but also to the lack of knowledge about the in-situ measurements of the mixing state of LAC with other aerosol species, which has a non-negligible impact on its radiative forcing (Jacobson, 2001). Also, there are uncertainties associated with the models, such as the Mie model and the radiative transfer models, which are used to derive aerosol radiative properties from available measurements (Wex et al., 2002) and the related aerosol physicochemical properties that are closely related to the radiative forcing (Moffet and Prather, 2009). Thus, it is of great importance to verify the reliability of the outputs from an optical model with the measured aerosol properties and to evaluate the uncertainties of calculations attributed to the uncertainties of measurements and models.

As a way to investigate the inherent relationship between aerosol optical properties and physicochemical characteristics, the Mie model was applied to reconstruct aerosol optical properties with measured size spectra and chemical composition as the input parameters (Bohren and Huffman, 2008). Closure studies based on in-situ measurements and the Mie model, with two extreme assumptions of the LAC mixing state, external mixture (LAC is distinct from other aerosol particles) and internal mixture (EC is incorporated homogeneously within the non-light-absorbing component in aerosol particles), were performed to verify the reliability of the model outputs by comparing the reconstructed and measured optical properties extensively and to identify the uncertainties associated with the input parameters and numerical models. Moreover, 
sensitivity experiments can be conducted based on the closure (Wex et al., 2002; Cheng et al., 2006; Cheng et al., 2008; Ma et al., 2011). In China, related studies were conducted at non-urban sites in the Pearl River Delta, North China Plain (Cheng et al., 2006; Ma et al., 2011), and a mountainous site in northern China (Shen, 2012). The studies presented reliable information about the aerosol optical properties associated with the aerosol physical and chemical characteristics in China. However, such researches were based on the assumption of external or homogeneously internal mixtures for LAC and non-light-absorbing component. Meanwhile, relatively low temporal and size resolution of LAC distribution determined by traditional filter membrane samplers (Höller et al., 2003) were used, which was a critical parameter in the Mie model. Recent studies suggested that the assumption of core-shell mixture, which was an LAC core surrounded by well-mixed non-absorbing components, was more appropriate in the evaluation of aerosol direct radiative forcing (Jacobson, 2000; Bohren and Huffman, 2008; Liu et al., 2012; Liu et al., 2014). To the best of our knowledge, very few related studies have been conducted that take these three factors into consideration, especially for aerosols at a background site in eastern China.

To fill in this gap, in-situ measurements were conducted at Mt. Huang (the Yellow Mountain), a continental background mountainous site in eastern China. In this study, the term "EC" (elemental carbon) is used instead of "LAC" to refer to the light-absorbing carbon because EC is the major ingredient of LAC at Mt. Huang and no other light-absorbing carbon was considered. This paper presents a spherical Mie model with assumptions of external and core-shell mixtures in which a two-component optical aerosol model and high size-segregated EC ratio were considered. The model outputs were verified by an aerosol optical closure study using the measured aerosol optical properties. The potential uncertainties in the model associated with the assumptions were discussed. The influence of high resolution of EC size and time distribution on the modeled aerosol optical properties were investigated via two sensitivity experiments. Finally, the uncertainties of calculation attributed to the uncertainties of measurements and model assumptions were evaluated with a Monte Carlo simulation. 


\section{Measurements}

\subsection{Site description}

The campaign was conducted at Mt. Huang $\left(30.12^{\circ} \mathrm{N}, 118.19^{\circ} \mathrm{E}\right)$ from September 30 to October 8 (274-282 day of year (DOY)), 2012, at a height of approximately $900 \mathrm{~m}$ above mean sea level. Mt. Huang is approximately $300 \mathrm{~km}$ southwest of the megacity cluster of the Yangtze River Delta and is a tourist region with few industrial activities. Fig. 1 shows the average distribution of aerosol optical depth over eastern China during the observation period and the location of Mt. Huang. The relatively low aerosol optical depth values around Mt. Huang indicates that this site is less affected by regional emissions compared to surrounding regions, and therefore, can be considered as a continental background mountainous site. In-situ measurements and a model study to analyze the aerosol optical parameters at this site could have the regional representation (Yuan et al., 2013; Chen et al. 2014; Li et al., 2014). 


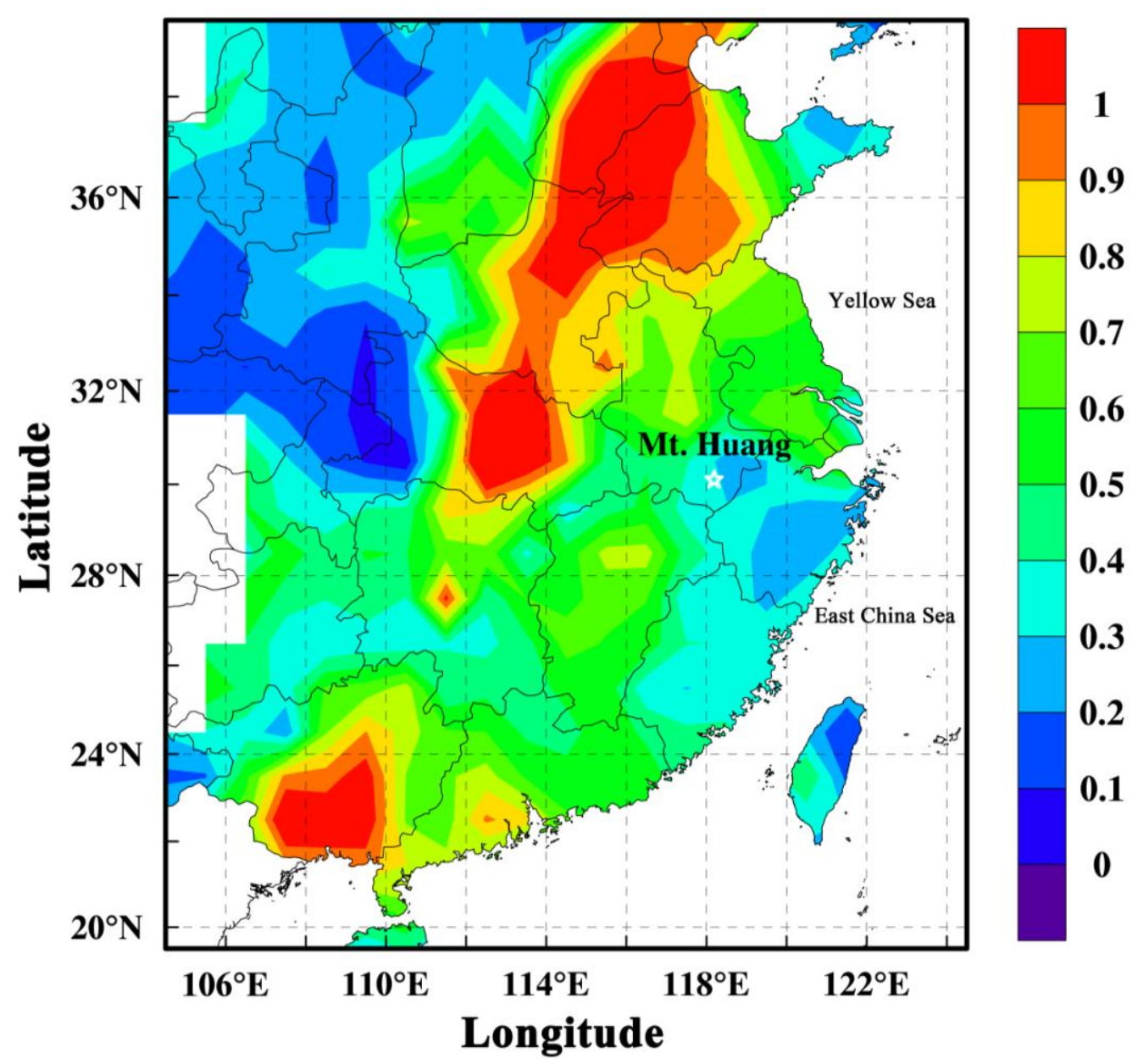

Fig. 1. A map of eastern China. The location of the observation site is marked with a star. The shaded contour represents the mean distribution of aerosol optical depth during 274 to 282 DOY, obtained from Moderate Resolution Imaging Spectroradiometer (MODIS) data.

\subsection{Aerosol sampling}

The data used in this study were collected in a temperature-controlled room during the campaign. A community air-sampling system, which was comprised a stainless steel pipe with a diameter of $3 / 4$ inch, put out the window to a height of approximately $8 \mathrm{~m}$ aboveground and a vacuum pump that was used to keep the aerosol flow rate at $10.97 \mathrm{~L} / \mathrm{min}$ in the sampling system, was installed in the room. Most of the instruments, including a scanning mobility particle sizer (SMPS) (Model 3936, TSI, St. Paul, MN, USA), an aerodynamic particle sizer (APS) (Model 3321, TSI, St. Paul, MN, USA), an integrating nephelometer (Model 3563, TSI, St. Paul, MN, USA), and an aethalometer (Model AE31, Magee Scientific, Berkeley, CA, USA) were 
incorporated at the end of the community air-sampling system. The sample flow was split to the different instruments through stainless steel tubes and conductive rubber tubes. A Nafion Dryer (PD-100T-24MSS, Perma Pure LLC, Lakewood, NJ, USA) was installed upstream of all the instruments to ensure that the relative humidity (RH) of the aerosol was below $20 \%$.

In addition, a single particle aerosol mass spectrometer (SPAMS) (Hexin Analytical Instrument Co., Ltd, Guangzhou, China) with a homemade silica gel diffusion dryer, linked to a separate inlet system with a flow rate of $0.08 \mathrm{~L} / \mathrm{min} \pm 2 \%$ was installed in parallel with the community air-sampling system.

Every two days, all the instruments except the SPAMS were shut down for 30 min for cleaning. Meteorological parameters such as wind speed (WS), wind direction (WD), temperature (T), and RH were measured simultaneously by an automatic meteorological station (Vantage Pro2, Davis, USA) which was located on the room's roof.

\subsubsection{Aerosol size distribution}

Aerosol particle number size distributions (PNSDs) with electrical mobility diameters from 10 $\mathrm{nm}$ to $500 \mathrm{~nm}$ were determined continuously by the SMPS, which consists of a differential mobility analyzers (DMA) (Model 3081, TSI, St. Paul, MN, USA) and a condensation particle counters (CPC) (Model 3772, TSI, St. Paul, MN, USA). The SMPS was calibrated with polystyrene latex spheres (The National Institute of Standards and Technology) and $\mathrm{NaCl}$ aerosols (Jeong et al., 2010). The sample flow rate of $0.3 \mathrm{~L} / \mathrm{min} \pm 2 \%$ and sheath-to-sample flow ratio of 10 used in the SMPS were calibrated every two days when the instrument was manually restarted. Inversion of the SMPS data was done with the method described by Stratmann and Wiedensohler (1996), which included the transfer functions of the DMA demonstrated by Birmili et al. (1997). The counting efficiency of the CPC measured prior to the campaign according to Wiedensohler et al. (1997) and the particle diffusion losses in the sampling tubes were also taken into consideration for correcting the SMPS data following the procedure described by Kulkarni et al. (2011).

The APS was operated to measure the PNSDs with aerosol aerodynamic diameters range from $500 \mathrm{~nm}$ to $20 \mu \mathrm{m}$. The sample flow rate of the APS was maintained $1 \mathrm{~L} / \mathrm{min} \pm 2 \%$ and was also calibrated routinely identical to the SMPS. Aerodynamic diameters measured by the APS were 
converted to Stokes equivalent diameters by dividing the square root of an assumed density of $1.70 \mathrm{~g} / \mathrm{cm}^{3}$ for dry aerosol. This density was calculated based on parallel research of the major chemical composition of aerosol particles from impactor analysis at Mt. Huang by Li et al. (2014). Additionally, the APS data were corrected for gravitation losses in the inlet system (Kulkarni et al., 2011).

Then, the whole PNSDs with diameters from $10 \mathrm{~nm}$ to $20 \mu \mathrm{m}$ were yielded by combining the data obtained by the SMPS and APS. Due to the synchronous size-resolved activation experiment with the SMPS (Gu, 2013), two PNSDs were available per hour for the post processing.

\subsubsection{Aerosol scattering and hemispheric backscattering coefficients}

The aerosol scattering coefficient $\left(\sigma_{\mathrm{sp}, \text { neph }}\right)$ and the hemispheric backscattering coefficient $\left(\sigma_{\mathrm{hbsp}}\right.$, neph) were measured by a three-wavelength $(450 \mathrm{~nm}, 550 \mathrm{~nm}$ and $700 \mathrm{~nm})$ integrating nephelometer. The nephelometer was calibrated with particle-free air as the low span gas and $\mathrm{CO}_{2}$ (purity 99.99\%) as the high span gas, prior to the campaign (Anderson and Ogren 1998). The flow rate maintained in the nephelometer was $7.76 \mathrm{~L} / \mathrm{min}$, corresponding to a temporal resolution of 5 minutes for the measurement. Zero baseline check was carried out automatically, once an hour, to ensure the stability of the instrument during the sampling period.

Note that the sensing angles of $\sigma_{\mathrm{sp} \text {, neph }}$ and $\sigma_{\mathrm{hbsp}}$, neph were restricted between $7^{\circ}$ and $170^{\circ}$ and between $90^{\circ}$ and $170^{\circ}$, respectively, due to the instrument's design constraints. The light source of the nephelometer could result in a non-ideal angular response (Anderson et al., 1996). This angular response was taken into consideration in the Mie calculations for this campaign instead of correcting the data measured by the nephelometer. A correction considering the diffusion losses in the nephelometer inlet was estimated following the method provided by Kleefeld et al. (2002) and Kulkarni et al. (2011).

\subsubsection{Aerosol absorption coefficient}

The aethalometer was operated in parallel with the SMPS to measure the EC mass concentration at 7 wavelengths $(370 \mathrm{~nm}, 470 \mathrm{~nm}, 520 \mathrm{~nm}, 590 \mathrm{~nm}, 660 \mathrm{~nm}, 880 \mathrm{~nm}$, and $950 \mathrm{~nm}$ ) with a time interval of 5 minutes. The optical attenuation of light from the LED lamps, produced 
when a beam of light transmitted through the quartz fiber filters on which the aerosols were continuously deposited, was detected by the aethalometer. The quantity of attenuation is linearly proportional to the amount of EC and was recorded as EC mass concentration automatically by the aethalometer using the algorithm provided by the manufacturer (Magee Scientific, 2005). In addition, the aethalometer was calibrated, and the flow rate was set to $2 \mathrm{~L} / \mathrm{min}$ with a variation of $\pm 2 \%$.

The absorption coefficient at $532 \mathrm{~nm}\left(\sigma_{\mathrm{ap}, 532}\right)$ was obtained by converting the EC mass concentration at $880 \mathrm{~nm}$ using equation (1), which was the result of inter-comparison between an aethalometer at $880 \mathrm{~nm}$ and a photoacoustic spectrometer at $532 \mathrm{~nm}$ in the Pearl River Delta region of China (Wu et al., 2009).

$$
\sigma_{\mathrm{ap}, 532}=8.28 \cdot M_{\mathrm{EC}, 880}+2.23
$$

where $\sigma_{\text {ap, } 532}$ is the absorption coefficient at $532 \mathrm{~nm}$ measured by photoacoustic spectrometer $\left(\mathrm{Mm}^{-1}\right), M_{\mathrm{EC},} 880$ is the EC mass concentration directly recorded by aethalometer without any corrections $\left(\mu \mathrm{g} / \mathrm{m}^{3}\right)$, and 8.28 is the conversion factor $\left(\mathrm{m}^{2} / \mathrm{g}\right)$, which varies for different sites (e.g. $10 \mathrm{~m}^{2} / \mathrm{g}$ was used for urban aerosols in Moosmüller et al. (1998), $7 \mathrm{~m}^{2} / \mathrm{g}$ for diesel soot (Fuller et al., 1999), and Zhuang et al. (2015) applied $11.05 \mathrm{~m}^{2} / \mathrm{g}$ for aerosols in Nanjing, a megacity in the Yangtze River Delta of China). The conversion factor of $8.28 \mathrm{~m}^{2} / \mathrm{g}$ used in this paper is within the range of $8-10 \mathrm{~m}^{2} / \mathrm{g}$ obtained in Mexico City (Barnard et al., 2007) and was applied in Beijing previously by Yan et al. (2008) and He et al. (2009). This factor may result in a conservative uncertainty of $20 \%$ for the calculation of the absorption coefficient due to the lack of comparison study at this site.

\subsubsection{Size-segregated EC ratio}

The SPAMS was deployed to measure the aerosol chemical composition in real-time. A similar technique was used in the first Aerosol Characterization Experiment (ACE-1) (Murphy et al., 1998). Li et al. (2011) reported design details and performance of the SPAMS. Standard polystyrene latex spheres were used to calibrate the SPAMS before observations (Li et al., 2011). Chen et al. (2014) described the setup of this instrument and the data processing used during this campaign. To investigate the influence of high resolution EC distribution on aerosol optical 
properties, three scenarios of $\mathrm{EC}$ ratios $\left(\varepsilon_{\mathrm{N}}\left(\log D_{\mathrm{p}}\right)_{\mathrm{EC}}\right)$ with aerodynamic diameters from 0.2 to 2.5 $\mu \mathrm{m}$, which was converted to Stokes equivalent diameter, were processed to put in the Mie model. The three scenarios include the high size-segregated EC ratio averaged over the study period with the same size bins of PNSDs, the hourly mean value of the EC ratio averaged across all size bins, and the hourly high size-segregated EC ratio.

\section{Methodology}

\subsection{Data processing}

The data from the first 5 minutes after the reboot of the instruments were manually eliminated, as were the data when the corresponding flow rate exceeded the range of the set value by more than $\pm 2 \%$ for the SMPS and APS and $\pm 5 \%$ for the other instruments. After data collection, the hourly arithmetic means of the filtered data obtained by the instruments of the community air-sampling system were calculated and used as input parameters in the model.

\subsection{The two-component optical aerosol model}

Aerosols in the atmosphere comprise various chemicals. To simplify the calculation, a two-component aerosol model with a light-absorbing component dominated by EC and a non-light-absorbing component that included sulfate, nitrate, ammonium, organic carbon, and undetermined compounds (Wex et al., 2002; Cheng et al., 2008; Ma et al., 2011), was applied to calculate the aerosol optical properties including light scattering, hemispheric backscattering, and the absorption coefficients in the present closure study.

According to the EC size-segregated number fraction $\left(\varepsilon_{\mathrm{N}}\left(\log D_{\mathrm{p}}\right)_{\mathrm{EC}}\right)$ measured by the SPAMS, the total PNSDs were partitioned into the particle number size distribution of $\mathrm{EC}\left(N\left(\log D_{\mathrm{p}}\right)_{\mathrm{EC}}\right)$ and non-light-absorbing component $\left(N\left(\log D_{\mathrm{p}}\right)_{\text {non_EC }}\right)$ as shown in equation (2) and (3):

$$
\begin{gathered}
N\left(\log D_{\mathrm{p}}\right)_{\mathrm{EC}}=N\left(\log D_{\mathrm{p}}\right)_{\text {measured }} \cdot \varepsilon_{\mathrm{N}}\left(\log D_{\mathrm{p}}\right)_{\mathrm{EC}} \\
N\left(\log D_{\mathrm{p}}\right)_{\text {non_EC }}=N\left(\log D_{\mathrm{p}}\right)_{\text {measured }}-N\left(\log D_{\mathrm{p}}\right)_{\mathrm{EC}}
\end{gathered}
$$

where $D_{\mathrm{p}}$ is the geometric diameters of the particles, and $N\left(\log D_{\mathrm{p}}\right)_{\text {measured }}$ is the PNSD measured by 
the SMPS and APS.

To calculate the optical properties of atmospheric aerosol particles, the refractive indices of those two components were needed as the input parameters of the Mie model (Bohren and Huffman, 2008). In this paper, the refractive index of EC was set as $\tilde{m}_{E C}=1.80-0.54 i$ according to previous studies about continental aerosols in China (Cheng et al., 2008; Ma et al., 2011; Shen, 2012). The refractive index of the non-light-absorbing component was set as $\tilde{m}_{n o n_{-} E C}=1.50-10^{-7} i$, a value based on the open literature listed by Cheng et al. (2006) and the previous studies by Cheng et al. (2008) and Wex et al. (2002).

\subsection{Mie model}

In this paper, the two-component aerosols were assumed to be completely externally mixed or core-shell mixed in the Mie model due to the lack of EC mixing state.

For the external mixture, the EC was mixed externally with the non-light-absorbing component. Thus, the scattering and hemispheric backscattering coefficients for external mixture ( $\left.\sigma_{\mathrm{sp} \text { (hbsp), ext }}\right)$ were expressed by the sum of scattering and hemispheric backscattering by these two components, respectively, both were integrated mathematically across all size bins based on the assumption of spherical particles according to the Mie model (Bohren and Huffman, 2008), which was described in equation (4):

$$
\begin{array}{r}
\sigma_{\text {sp (hbsp), ext }}=\int_{D_{\mathrm{p}}} Q_{\mathrm{sp}(\mathrm{hbsp}), \mathrm{EC}} \cdot \frac{\pi D_{\mathrm{p}}^{2}}{4} \cdot N\left(\log D_{\mathrm{p}}\right)_{\mathrm{EC}} \cdot d \log D_{\mathrm{p}} \\
+\int_{D_{\mathrm{p}}} Q_{\mathrm{sp}(\mathrm{hbsp}) \text {, non_EC }} \cdot \frac{\pi D_{\mathrm{p}}^{2}}{4} \cdot N\left(\log D_{\mathrm{p}}\right)_{\text {non_EC }} \cdot d \log D_{\mathrm{p}}
\end{array}
$$

where $Q_{\text {sp(hbsp), EC }}$ and $Q_{\text {sp(hbsp), non_EC }}$ are the scattering and backscattering efficiencies for EC and non-light-absorbing component, respectively (dimensionless values). They are functions of scattering angle, refractive index, and the dimensionless size parameter in the Mie model (Cheng et al., 2006; Bohren and Huffman, 2008).

Whereas for the core-shell mixture, EC was assumed as an absorbing spherical core surrounded by a mantle of non-absorbing component. As a crucial parameter for calculating the optical properties, the sizes of the EC cores in the particles with the same diameter could be generally 
different. To simplify the optical aerosol model, the core-shell mixed particles with the same diameter were assumed to have an EC core of the same size (Ma et al., 2012), which was calculated as:

$$
D_{\text {core }}\left(D_{\mathrm{p}}\right)=D_{\mathrm{p}} \cdot\left(N\left(\log D_{\mathrm{p}}\right)_{\mathrm{EC}} / N\left(\log D_{\mathrm{p}}\right)_{\text {measured }}\right)^{\frac{1}{3}}
$$

where $D_{\text {core }}\left(D_{\mathrm{p}}\right)$ is the diameter of the EC core at size $D_{\mathrm{p}}$.

Then, the scattering and hemispheric backscattering coefficients for core-shell mixture ( $\sigma_{\mathrm{sp} \text { (hbsp), }}$ core-shell) were calculated by:

$$
\sigma_{\text {sp (hbsp), core-shell }}=\int_{D_{\mathrm{p}}} Q_{\mathrm{sp}(\mathrm{hbsp}) \text {, core-shell }} \cdot \frac{\pi D_{\mathrm{p}}^{2}}{4} \cdot N\left(\log D_{\mathrm{p}}\right) \cdot d \log D_{\mathrm{p}}
$$

where $Q_{\text {sp(hbsp), core-shell }}$ is the scattering or backscattering efficiency for the core-shell mixed aerosols.

The angle truncation and the non-ideal angular response of the nephelometer mentioned in Section 2.2.2 were considered in the Mie calculations. Therefore, Q in equations (4) and (6) was replaced by corrected ones (Cheng et al., 2006; Bohren and Huffman, 2008) based on the nephelometer angular response obtained by Anderson et al. (1996). Finally, the value of $\sigma_{\mathrm{sp} \text { (hbsp), ext }}$ (core-shell) was obtained by simulating the signals corresponding to the nephelometer and aethalometer measurements. $\sigma_{\text {ap (hbsp), ext (core-shell) }}$ is then obtained by:

$$
\sigma_{\mathrm{ap}, \text { ext(core-shell) }}=\sigma_{\text {extinction, ext(core-shell) }}-\sigma_{\mathrm{sp}, \text { ext(core-shell) }}
$$

where $\sigma_{\text {extinction, ext (core-shell) }}$ is the extinction coefficient, which is obtained the same way as the scattering coefficient.

\section{Results and discussion}

\subsection{Comparisons of calculated and measured aerosol optical properties}

An optical closure study using the first EC ratio scenario was performed by comparing the calculated aerosol scattering coefficient at three wavelengths $(450 \mathrm{~nm}, 550 \mathrm{~nm}, 700 \mathrm{~nm})$ and the aerosol absorption coefficient at $550 \mathrm{~nm}$ with the corresponding measured values. $\sigma_{\mathrm{ap}, 532}$ was used as the measured absorption coefficient in the closure study due to the insensitivity of absorption 
coefficient to minor changes in wavelength (He et al., 2009). Discussions of the aerosol hemispheric backscattering coefficient were excluded which will be analyzed in a follow-up study.

The average values of $\sigma_{\mathrm{sp}, \text { ext }}, \sigma_{\mathrm{sp}, \text { neph }}$, and $\sigma_{\mathrm{sp} \text {, core-shell }}$ at $550 \mathrm{~nm}$ were $105.1 \mathrm{Mm}^{-1}, 103.1 \mathrm{Mm}^{-1}$, and $94.7 \mathrm{Mm}^{-1}$, respectively. The respective average values of $\sigma_{\text {ap, ext }}, \sigma_{\text {ap, } 532}$ and $\sigma_{\text {ap, core-shell }}$ at 550 nm were $11.1 \mathrm{Mm}^{-1}, 18.3 \mathrm{Mm}^{-1}$, and $25.6 \mathrm{Mm}^{-1}$. The average $\sigma_{\mathrm{sp} \text {, ext }}$ was 1.11 times higher than $\sigma_{\mathrm{sp}}$, core-shell, whereas the mean $\sigma_{\mathrm{ap}}$, core-shell was obviously larger than $\sigma_{\mathrm{ap}, \text { ext }}$ by a factor of 2.31. So aerosol absorption coefficient was more sensitive to EC mixing state compared to the scattering coefficient because of the "focusing effect" of core-shell mixed aerosol that leads to more radiation interacting with the EC core and consequently more light getting absorbed (Horvath, 1993). Compared to other studies in which a homogeneous internal mixture was assumed in the Mie model, the factor in our study for calculated scattering coefficient was not much different from the result obtained at Wuqing in the North China Plain (1.10) (Ma et al., 2011), but was slightly smaller than that at Xinken in the Pearl River Delta region of Southern China (1.20) (Cheng et al., 2006) and in Germany (1.20) (Wex et al., 2002). However, the factor for the calculated absorption coefficient was larger than the result (2.04) demonstrated by Wex et al. (2002) but consistent with the factors of 2.32 and 2.30 reported by Ma et al. (2011) and Cheng et al. (2006), respectively. This indicated that the aerosols at the background site in eastern China could have similar optical properties as those over northern, eastern, and southern China.

For quantification of the discrepancy between the calculated and measured values, a relative difference $\left(\Delta\left(\sigma_{\mathrm{sp}(\mathrm{ap}), \lambda}\right)\right)$ was defined as:

$$
\Delta\left(\sigma_{(\mathrm{sp}(\mathrm{ap}), \lambda)}\right)=\frac{\sigma_{(\mathrm{sp}(\mathrm{ap}), \operatorname{ext}(\mathrm{core}-\mathrm{shell}), \lambda)}-\sigma_{(\mathrm{sp}(\mathrm{ap}), \text { neph }, \lambda)}}{\sigma_{(\mathrm{sp}(\mathrm{a} \mathrm{pn)} \mathrm{e} \mathrm{p} \mathrm{p} \lambda)},}
$$

where $\sigma_{\mathrm{sp} \text { (ap), ext (core-shell), } \lambda}$ and $\sigma_{\mathrm{sp} \text { (ap), neph, } \lambda}$ are the calculated and measured scattering coefficients at wavelength $\lambda$, respectively.

Aerosol particles in the atmosphere are probably externally mixed in part and core-shell mixed in another part. Therefore, the value measured by the nephelometer should fall within the range determined by the calculated values for the external and core-shell mixtures. This means that $\Delta\left(\sigma_{\mathrm{sp}}\right)$ is generally positive for the external mixture and negative for the core-shell mixture, whereas $\Delta\left(\sigma_{\mathrm{ap}}\right)$ is the opposite under the ideal condition. Fig. 2 showed that $\Delta\left(\sigma_{\mathrm{sp}}\right)$ at $550 \mathrm{~nm}$ ranged from $-20.1 \%$ to $28.9 \%$ for external mixture and from $-28.8 \%$ to $16.6 \%$ for core-shell mixture. It is worth 
noting that from 280 to 282 DOY (October 6 to 8,2012 ), the $\Delta\left(\sigma_{\mathrm{sp}}\right)$ for external mixture was occasionally negative and for core-shell mixture reached the minimum, indicating that the calculated scattering coefficient could underestimate the measured one. This can be explained by the restrictive model assumption that all particles were spherical. However, aerosols are sometimes nonspherical in the ambient atmosphere, especially the soot aggregates and some large particles such as mineral dust particles and sea-salt aerosols (Chamaillard et al., 2006; Kaaden et al., 2009). Kleefeld et al. (2002) and Chamaillard et al. (2006) have reported that the spherical Mie model would underestimate the real scattering as particle diameters increased. The variation of the measured backscattering ratio $(\beta)$ (the fraction of hemispheric backscattering coefficient to the total scattering coefficient measured by nephelometer) could reflect the change in bulk diameter of aerosols to a certain extent. As shown in Fig. 2, a decreasing trend was seen during 280 to 282 DOY, indicating an increasing particle diameter on those days, which could lead to an underestimation of the calculated scattering. Whereas, for the absorption coefficient, almost all the $\Delta\left(\sigma_{\mathrm{ap}}\right)$ were consistent with the ideal condition except for the early of 278 DOY when the measured values reached the lowest of the period, which could result in large measurement uncertainty. Additionally, the values of $\Delta\left(\sigma_{\mathrm{ap}}\right)$ ranged from $-76.5 \%$ to $-15.0 \%$ for external mixture and widely from $-48.0 \%$ to $113.0 \%$ for core-shell mixture. This can be readily understood because, as mentioned in the second paragraph of this section, the "focusing effect" enhances the light absorption.

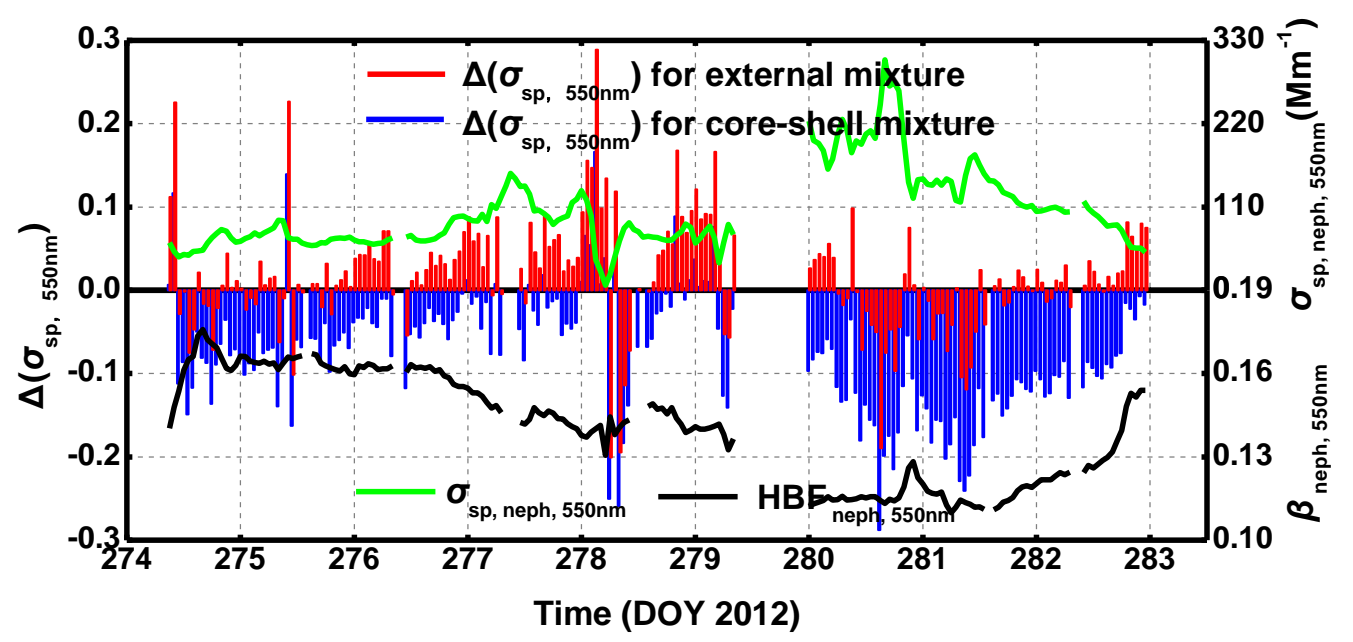




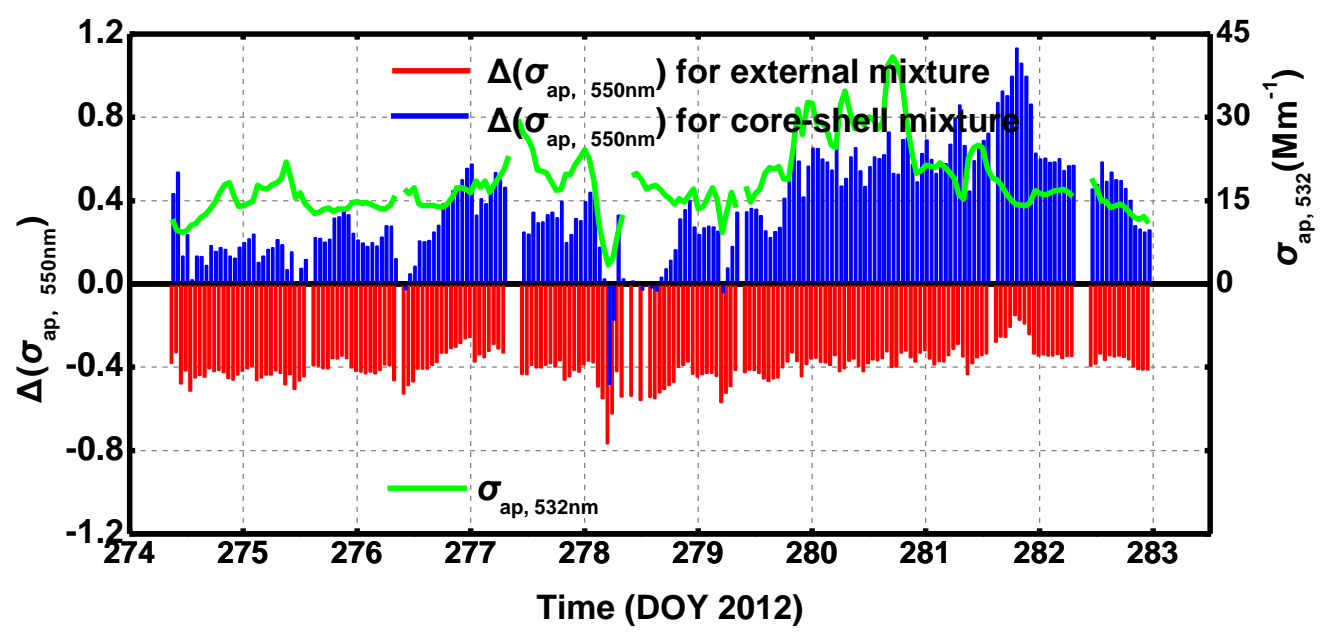

Fig. 2. Time series of the relative difference and the measured scattering and absorption coefficients as well as backscattering ratio at $550 \mathrm{~nm}$.

The mean values of $\Delta\left(\sigma_{\mathrm{sp}}\right)$ at all three wavelengths as well as $\Delta\left(\sigma_{\mathrm{ap}}\right)$ at $550 \mathrm{~nm}$ were listed in Table 1. Generally, it showed relatively low absolute values of $0.7 \%-8.8 \%$ for $\Delta\left(\sigma_{\mathrm{sp}}\right)$ compared to previous studies of $-35 \%-50 \%$ in Wex et al. (2002) and -16\%-27\% in Cheng et al. (2006) whereas for $\Delta\left(\sigma_{\mathrm{ap}}\right)$, it was $-39.6 \%$ for external mixture and $37.3 \%$ for core-shell mixture, respectively, which agreed with the ideal condition. It should be noted that these discrepancies were not enormous due to that Mt. Huang was a continental background mountainous site in eastern China, the scattering and absorption coefficients were relatively small as compared to that at urban sites (Yuan et al., 2013). Therefore, a minor discrepancy could result in relatively large values of $\Delta\left(\sigma_{\mathrm{sp}}\right)$ and $\Delta\left(\sigma_{\mathrm{ap}}\right)$.

Fig. 3 showed the scatterplots of the calculated versus measured values. It can be seen that the slopes $(b)$ of linear fitting were very close to 1 (line 1:1 shown in Fig. 3) for the scattering coefficient at all three wavelengths, 0.61 for the absorption coefficient with the assumption of the external mixture, and 1.44 for the core-shell mixture assumption. The correlation coefficients $\left(R^{2}\right)$ were all above 0.98 . From this, a conclusion can be drawn that the Mie model with high size-segregated EC ratio averaged over the study period represented well the measured optical properties, confirming the reliability of the other measured aerosol properties as well.

Table 1 Average relative difference between the calculated and measured scattering $\left(\Delta\left(\sigma_{\mathrm{sp}}\right)\right)$ and absorption coefficients $\left(\Delta\left(\sigma_{\mathrm{ap}}\right)\right)$ and the corresponding standard deviations. 


\begin{tabular}{llclc}
\hline & \multicolumn{2}{c}{$\Delta\left(\sigma_{\mathrm{sp}}\right)(\%)$} & \multicolumn{2}{c}{$\Delta\left(\sigma_{\mathrm{ap}}\right)(\%)$} \\
\hline$\lambda(\mathrm{nm})$ & External & Core-shell & External & Core-shell \\
450 & $1.6 \pm 6.1$ & $-8.8 \pm 6.8$ & & \\
550 & $1.8 \pm 6.6$ & $-7.5 \pm 7.2$ & $-39.6 \pm 7.6$ & $37.3 \pm 24.4$ \\
700 & $7.9 \pm 7.6$ & $-0.7 \pm 7.8$ & & \\
\hline
\end{tabular}
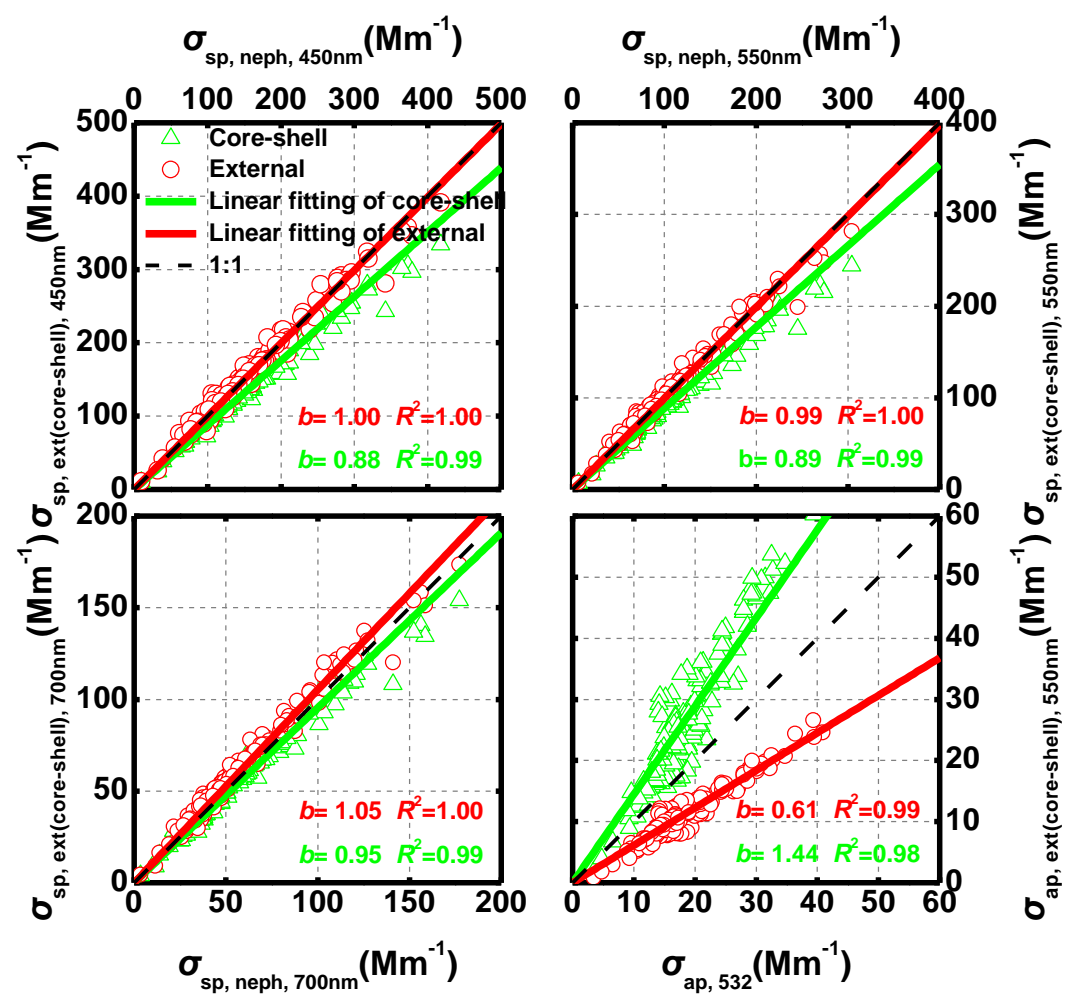

Fig. 3. Scatterplots of calculated and measured scattering coefficients at three wavelengths as well as the absorption coefficients at $550 \mathrm{~nm}$. The black dash line denotes the 1:1 reference lines.

\subsection{Potential uncertainties in the model associated with the assumptions}

Despite the successful closure achieved in this study, several issues still exist, which could contribute to discrepancies in the calculations, especially for the light absorption.

Firstly, aerosol particles were assumed to be spherical in the Mie model as discussed in Section 4.1. This could contribute to the underestimation of the calculated scattering for larger sizes; however, this underestimation would be limited. Fig. 4 showed the average aerosol particle size distribution during the study and the cumulative contributions of aerosols with different sizes to the optical properties calculated by the Mie model. The scattering and absorption coefficients were 
dominated by the particles with diameters ranging from $150 \mathrm{~nm}$ to $1000 \mathrm{~nm}$ despite the large numbers of aerosol particles with diameters less than $150 \mathrm{~nm}$, indicating that the optical properties were mainly dominated by the accumulation mode spherical particles (Ma et al, 2012). However, freshly generated EC aggregates, which were generally less than $150 \mathrm{~nm}$ (Moffet and Prather, 2009; Ma et al, 2012), and the generally nonspherical larger particles, such as mineral dust particles and sea-salt aerosols, lay outside of the optically active size range, and their relative optical contribution was less than $10 \%$. Additionally, the concentration of EC and large particles at Mt. Huang were very low due to the quick aging processing of EC (Riemer et al., 2004) and no dust event or air mass from the sea was observed during the study.
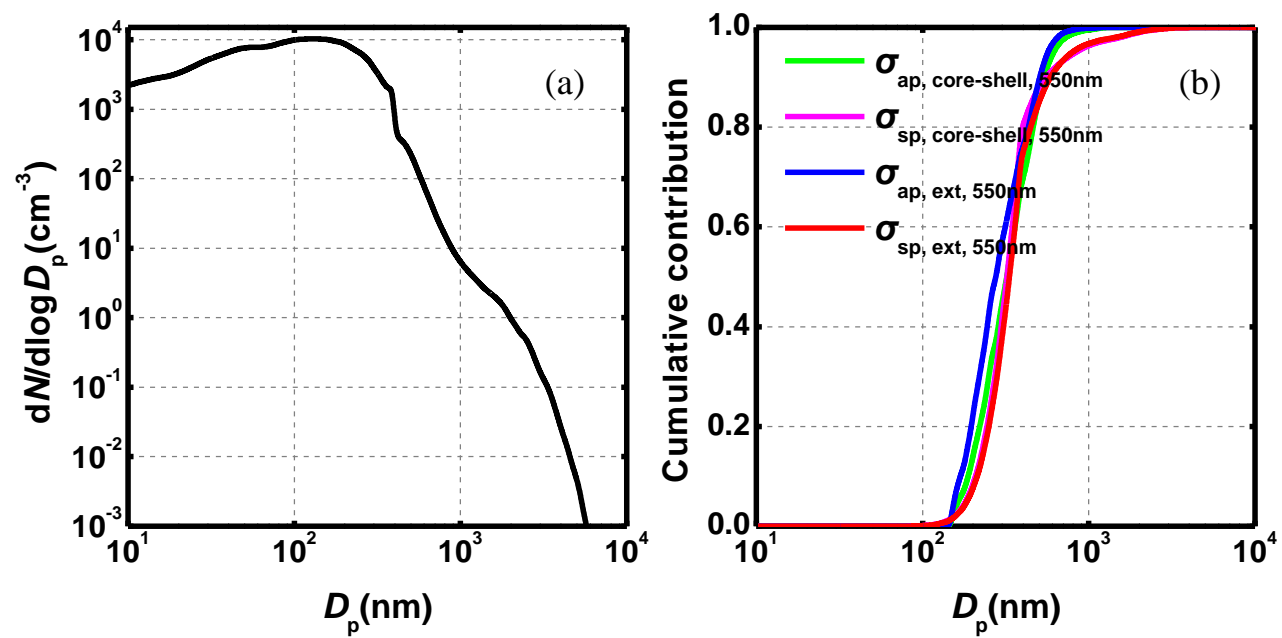

Fig. 4. Average aerosol particle size distribution during the study (a) and the cumulative contributions of different-size aerosols to the optical properties based on the Mie model (b).

Secondly, the diameter, $D_{\mathrm{p}}$ used as input for the Mie model to calculate the optical properties was the geometric mean diameter for each size bin of the SMPS and APS. However, it is not realistic that all the particles sized by the instruments for each size bin are monodisperse with a diameter of $D_{\mathrm{p}}$. This could contribute to the discrepancy between the modeled and measured optical properties, due to the large influence of diameter on the calculation (Wex et al, 2002). So further improvement in the measurement of size distribution with higher spectral resolution is needed.

Thirdly, EC was the only component considered to absorb sunlight. However, some other LAC species, such as a few of organic carbon species known as "brown carbon $(\mathrm{BrC})$ ", were also found 
to also absorb visible light (Andreae and Gelencsér, 2006). Feng et al. (2013) and Lu et al. (2015) showed that although $\mathrm{BrC}$ absorbed strongly in the ultraviolet wavelengths and less significantly in the visible wavelengths compared to EC, it could play an important role in estimating radiative forcing. However, Cheng et al. (2008) found that the light absorption of $\mathrm{BrC}$ contributed little (1-2\%) to the total light absorption at Xinken and Yufa, two polluted sites in northeastern and southern China, respectively. Thus, large uncertainties and difficulties in estimating the absorptivity of $\mathrm{BrC}$ still exist. In our study, we used the EC mass concentration at $880 \mathrm{~nm}$ to calculate the absorption coefficient as the measured value to minimize effectively the interference from light-absorbing organic carbon (Zhuang et al., 2014).

Last but not least, the size-segregated EC ratio used in the Mie model was the period average with aerodynamic diameters from 0.2 to $2.5 \mu \mathrm{m}$, which corresponded to Stokes equivalent diameters of $0.15-1.92 \mu \mathrm{m}$. The low time resolution and restricted diameter range could have influenced the discrepancies between the model outputs and the measurements. However, as mentioned in the first issue, the optical contribution of aerosol particles smaller than $0.15 \mu \mathrm{m}$ or larger than $1.92 \mu \mathrm{m}$ was very small, therefore, this restriction was neglected in the Mie model calculation. For the influence of low time resolution of the EC ratio on the model outputs, we performed two sensitivity experiments in the next section.

\subsection{Sensitivity experiments}

To investigate the importance of high resolution EC distribution on aerosol optical properties. two sensitivity experiments were performed. In the first experiment (exp1), the hourly mean value of the EC ratio averaged across all size bins was processed as the uniform EC ratio for each size in the Mie model, whereas in the second experiment (exp2), the hourly high size-segregated EC ratio was used.

Fig. 5 presented the time series of calculated and measured optical properties at $550 \mathrm{~nm}$ reconstructed from the two experiments and Fig. 6 showed the scatterplots of calculated versus measured results with fitting lines and corresponding $b$ and $R^{2}$ values for the two experiments. The same trends and near-perfect agreements with $b$ s close to 1 and with $R^{2}$ s larger than 0.98 between the retrieved and measured scattering coefficients were achieved in both experiments. 


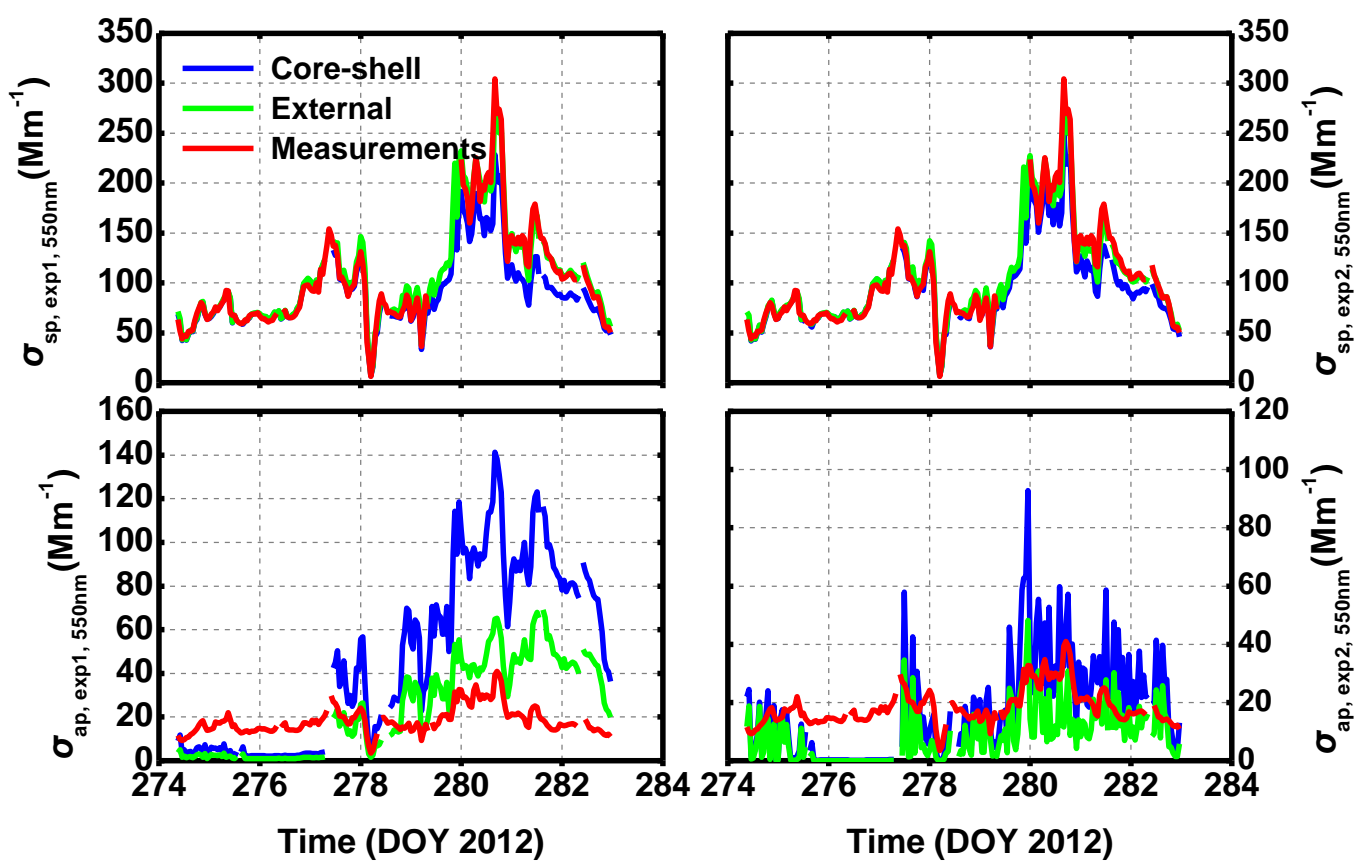

Fig. 5. Time series of calculated and measured scattering and absorption coefficients at $550 \mathrm{~nm}$ reconstructed from the two sensitivity experiments.
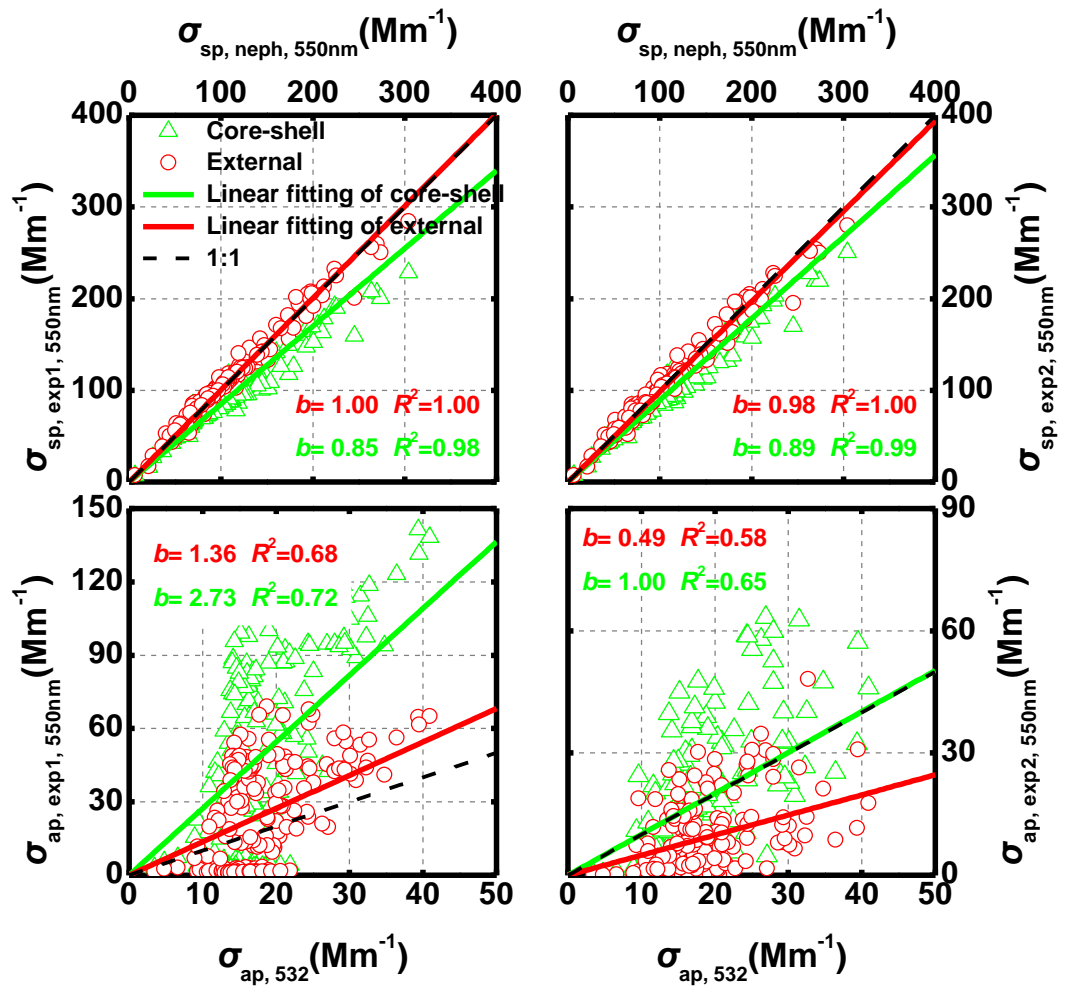

Fig. 6. Scatterplots of calculated and measured scattering and absorption coefficients at $550 \mathrm{~nm}$ for the two sensitivity experiments. The black dash line denotes the 1:1 reference lines. 
However, a relatively weak correlation was found between the calculated and measured absorption coefficients. In the first experiment, the Mie model underestimated the measured values before 277.5 DOY and overestimated them thereafter. The modeled values deviated from the trend of the measured ones for both the external and core-shell mixtures, mainly due to the increase of EC ratio in the mid- to late-period (Chen et al., 2014). In the second experiment, ideally, the result of the Mie model with the hourly high size-segregated EC ratio should have the best agreement with the measurements due to the high concordance with the measured aerosol properties. However, large fluctuations appeared in the time series of the modeled values, even though the overall trend of the modeled values fit that of the measured values. This was due to the limitation of the SPAMS and data processing (Chen et al., 2014), which contributed to the dispersion of data points in Fig. 6 and thus the poor correlations with relatively low $R^{2}$ s, ranging from 0.58 to 0.72 .

Additionally, the discrepancies between the two experiments and the closure study were less than $2 \%$ for the calculated scattering coefficient, whereas for the modeled absorption coefficient, the discrepancies increased to $-27 \%-98 \%$. Therefore, a conclusion could be drawn that different scenarios of $\varepsilon_{\mathrm{N}}\left(\log D_{\mathrm{p}}\right)_{\mathrm{EC}}$ had negligible effects on the calculated scattering coefficient. This result was consistent with the result at Mt. Tai in eastern China demonstrated by Shen (2012). However, the EC ratio had an obvious effect on the calculated absorption coefficient. According to the two experiments, the high size-segregated EC ratio averaged over the study period in the closure was enough to reconstruct the aerosol absorption coefficient in the Mie model; namely, the EC size resolution was more important than its time resolution in retrieving the absorption coefficient and thus in estimating the radiative forcing of aerosols.

\subsection{Uncertainties of the aerosol optical closure study}

To evaluate the uncertainties of calculation due to the uncertainties of measurements and model assumptions, a Monte Carlo simulation was carried out by repeating the Mie calculation. For each repetition, all input parameters were changed simultaneously and randomly in the Mie model. Deviations of those input parameters were supposed to be normally distributed around the original value with relative standard deviation, $s$. The uncertainty of each parameter was considered to be 3 
times $s(3 s)$ because a range of $\pm 3 s$ around the original value covers $99 \%$ of the values possible for those parameters (99\% confidence level) (Table 2).

Table 2 Uncertainties of each input parameter for the Mie model, given in terms of one relative standard deviation $(s)$.

\begin{tabular}{ll}
\hline Parameters & Standard deviation $(\%)$ \\
\hline$D_{\mathrm{P}, \text { DMA }}$ & $1.2^{\mathrm{a}}$ \\
$N_{\mathrm{CPC}}$ & $3.3^{\mathrm{a}}$ \\
$D_{\mathrm{p}, \mathrm{APS}}$ & $3.0^{\mathrm{b}}$ \\
$N_{\mathrm{APS}}$ & $3.3^{\mathrm{b}}$ \\
$\tilde{m}_{r, \text { non_EC }}=1.50$ & $0.3^{\mathrm{c}}$ \\
$\tilde{m}_{r, E C}=1.80$ & $3.3^{\mathrm{c}}$ \\
& \\
$\tilde{m}_{i, E C}=0.54$ & $13.3^{\mathrm{c}}$ \\
$\varepsilon_{\mathrm{v}}\left(D_{\mathrm{p}}\right)_{\mathrm{EC}, \text { SPAMS }}$ & \\
$\sigma_{\mathrm{sp}, \text { bsp neph }}$ & $6.7^{\mathrm{d}}$ \\
$\sigma_{\mathrm{ap}, 532}$ & $2.3^{\mathrm{e}}$ \\
\hline
\end{tabular}

${ }^{a}$ The uncertainty of the SMPS consisted of the measurement uncertainties of the DMA and CPC. In addition, uncertainty due to the DMA inversion program was also considered (Wiedensohler et al., 2012).

${ }^{b}$ The uncertainty of the APS was from the references of Wex et al. (2002) and Peters and Leith (2003) and the uncertainty due to the conversion from aerodynamic to Stokes equivalent diameter. ${ }^{\mathrm{c}}$ The uncertainties of refractive indices were assigned based on the open literature listed by Cheng et al. (2006). The large uncertainty of the imaginary part was caused by the diversity of EC.

${ }^{\mathrm{d}}$ The uncertainty of EC volume size distribution was estimated by considering uncertainties of the size measurement and of the analysis in volume fraction, according to the results of Chen et al. (2014).

${ }^{\mathrm{e}}$ Anderson et al. (1996).

${ }^{\mathrm{f}} \mathrm{Wu}$ et al. (2009) and He et al. (2009).

For the Mie model calculations, 1000 runs were sufficient for convergence of the mean value and the standard deviation (the relative difference between the mean value of those 1000 runs and 
the calculated values in Section 4.1 were less than 1\%). Table 3 summarizes the mean relative standard deviations $\left(s_{\mathrm{Mie}}\right)$ of the calculated aerosol optical properties derived from the Monte Carlo simulation. The uncertainties of the calculated optical properties were considered to be $3 s_{\mathrm{Mie}}$ at a $99 \%$ confidence level. For the external mixture, the average uncertainties of calculated scattering and absorption coefficients were approximately $\pm 6 \%$ and $\pm 14 \%$, respectively. For the core-shell mixture, the respective uncertainties for the calculated scattering and absorption coefficients were $\pm 9 \%$ and $\pm 31 \%$. The uncertainties calculated for the scattering coefficient in the closure study were lower than that of previous studies. However, the uncertainty of the absorption coefficient for the core-shell mixture is almost similar with other results for the internal mixture (Wex et al., 2002; Cheng et al., 2006; Ma et al., 2011). It should be noted that the overall uncertainties would have decreased if the same uncertainty of $\tilde{m}_{i, E C}$ as Cheng et al. (2006) had been applied. Compared to the differences from the other studies, the Mie model with high resolution of the EC ratio size distribution observed by the SPAMS in this study had a non-negligible effect on improving the inversion of the calculated absorption.

Table 3 Relative standard deviation $\left(s_{\text {Mie }}\right)$ of the calculated scattering and absorption coefficients calculated by the Monte Carlo simulation.

\begin{tabular}{ccccc}
\hline & \multicolumn{2}{c}{$s_{\text {Mie }}$ for $\sigma_{\text {sp }}(\%)$} & \multicolumn{2}{c}{$s_{\text {Mie }}$ for $\sigma_{\text {ap }}(\%)$} \\
\cline { 2 - 5 }$\lambda$ & External & Core-shell & External & Core-shell \\
\hline 450 & 2.0 & 2.9 & & \\
550 & 2.1 & 3.0 & 4.7 & 10.2 \\
700 & 2.2 & 3.1 & & \\
Average & 2.1 & 3.0 & & \\
\hline
\end{tabular}

Fig. 7 depicted the time series of calculated and measured optical properties at $550 \mathrm{~nm}$. Breaks of the measured values occurred when the instruments were powered off during rain events. In Fig. $7 \mathrm{a}, \sigma_{\mathrm{sp} \text {, neph }}$ was represented by white circles with uncertainties described by error bars. $\sigma_{\mathrm{sp} \text {, ext }}$ and $\sigma_{\mathrm{sp} \text {, core-shell }}$ corresponded to the upper and lower limits of the red shadow, respectively. The green shadow denoted the range that $\sigma_{\mathrm{sp} \text {, ext }}$ plus the uncertainties and $\sigma_{\mathrm{sp} \text {, core-shell }}$ minus the uncertainties 
obtained by the Monte Carlo simulation. In Fig. $7 \mathrm{~b}, \sigma_{\mathrm{ap}, 532}$ was represented by white circles with uncertainties described by error bars. Contrary to the scattering coefficients, $\sigma_{\text {ap, core-shell }}$ and $\sigma_{\text {ap, ext }}$ were the upper and lower boundaries of the red shadow, respectively. The green shadow denoted the range that $\sigma_{\text {ap, core-shell }}$ plus the uncertainties and $\sigma_{\text {ap, ext }}$ minus the uncertainties from the Monte Carlo simulation. The green shadows in Fig. 7 represented the possible regions where the measured values could be fallen. Table 4 listed the fractions of $\sigma_{\mathrm{sp} \text {, neph }}$ and $\sigma_{\mathrm{ap}, 532}$ included in the possible regions at three wavelengths. The trends of the modeled and measured values were almost the same for both the scattering and absorption coefficients. Approximately $90 \%$ of $\sigma_{\mathrm{sp} \text {, neph }}$ fell within the region of the Mie model calculations at all three wavelengths. For the absorption coefficient, over $99 \%$ of all the measured values were enclosed by the corresponding calculated bounding values. This result additionally confirmed the high quality of the gained data.

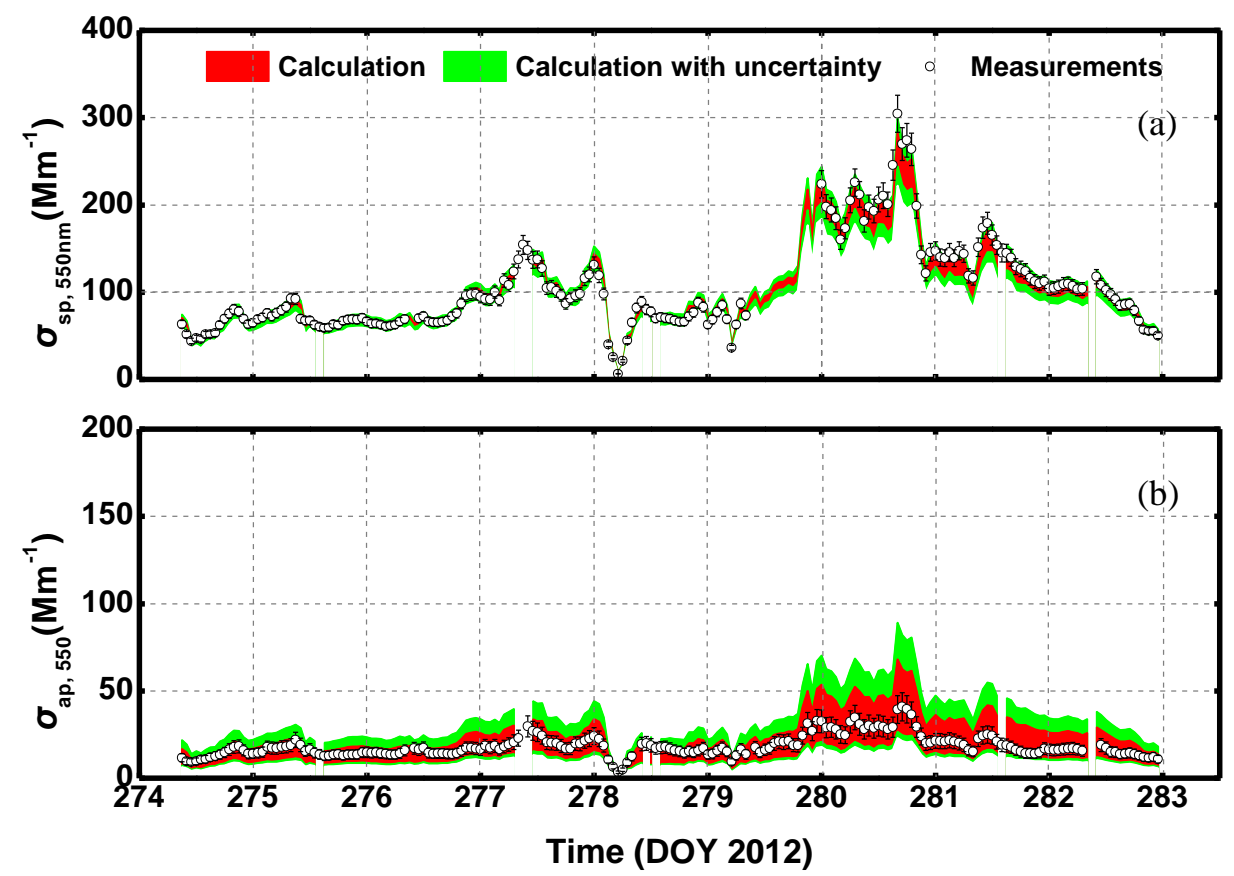

Fig. 7. Time series of calculated and measured scattering and absorption coefficients $550 \mathrm{~nm}$ during the observation period.

Table 4 Percentage of the measured data points that fell within the possible range derived from the Mie model calculations.

\begin{tabular}{lllll}
\hline & \multicolumn{2}{c}{$\sigma_{\text {sp }}(\%)$} & \multicolumn{2}{c}{$\sigma_{\text {ap }}(\%)$} \\
\cline { 2 - 4 }$\lambda(\mathrm{nm})$ & Without & With & Without & With \\
\hline
\end{tabular}




\begin{tabular}{lllll}
\cline { 2 - 4 } & uncertainty & uncertainty & uncertainty & uncertainty \\
\hline 450 & 61.3 & 89.0 & & \\
550 & 54.1 & 87.8 & 96.4 & 99.5 \\
700 & 47.0 & 90.0 & & \\
\hline
\end{tabular}

Similar to the other in-situ measurements, this study was conducted at only one continental background mountainous site; therefore, the representativeness has its limitation and cannot incorporated into the regional numerical models or the global climate models. However, this study provided an insight into the inherent relationship between aerosol optical properties and physicochemical characteristics in eastern China, which could supplement the database of aerosol optical properties for background sites in eastern China, along with the related studies in northern and southern China (Cheng et al., 2008; Ma et al., 2011). Furthermore, the method used in this study, including the Mie model and the assumption of a core-shell mixture with a high resolution of size-segregated EC ratio, could provide a platform for further research on the mixing state of $\mathrm{EC}$, and to investigate the factors influencing the radiative properties of aerosols. The numerical model should also consider the precise EC distribution to further improve the estimation of aerosol radiative forcing globally. Meanwhile, the measurement techniques of aerosol properties urgently needed improvement, especially for the identification, size distribution, and refractive indices of EC, so that they could entered accurately into regional and global climate models.

\section{Summary and conclusions}

This paper described an aerosol optical closure study performed in 2012 that verified model outputs by using the measured aerosol optical properties at Mt. Huang, a continental background mountainous site. A two-component optical aerosol model and a spherical Mie model with assumptions of external and core-shell mixtures were used. The potential uncertainties in the model associated with the assumptions were discussed, and the influence of high resolution of EC size and time distribution on the modeled aerosol optical properties were also investigated. Finally, the uncertainties of calculation attributed to the uncertainties of measurements and model 
assumptions were explored.

The closure study showed that the calculated scattering coefficient for the external mixture was 1.11 times higher than that for the core-shell mixture. Whereas for the aerosol absorption coefficient, the calculated value for the core-shell mixture was larger than that for the external mixture by a factor of 2.31 , which indicated the high sensitivity of aerosol mixing state on the absorption coefficient when compared to the scattering coefficient. Although several issues still exist, (e.g., the model assumption, the diameter restriction, etc.) which could contribute to the discrepancies in the calculations, the excellent agreement between the measured and calculated optical properties with correlation coefficients above 0.98 revealed that the Mie model with a high size-segregated EC ratio averaged over the study period was enough to reconstruct the aerosol absorption coefficient in the Mie model. The EC size resolution was more important than its time resolution in retrieving the absorption coefficient and thus in estimating the radiative forcing of aerosols.

The Monte Carlo simulation yielded the average uncertainties of approximately $\pm 6 \%$ and $\pm 14 \%$ for the calculated scattering and absorption coefficients, respectively, for the external mixture at a 99\% confidence level. For the core-shell mixture, the respective uncertainties for the calculated scattering and absorption coefficients were $\pm 9 \%$ and $\pm 31 \%$. Approximately $90 \%$ of the measured scattering at three wavelengths and $99 \%$ of the measured absorption at $550 \mathrm{~nm}$ were found to be enclosed by the possible range of Mie model calculations when considering the uncertainties of the calculated and measured values.

This study provided an insight into the inherent relationship between aerosol optical properties and physicochemical characteristics in eastern China and could supplement the database of aerosol optical properties for background sites in eastern China, by adding to the related studies in northern and southern China. Furthermore, the method used here provided a platform for further research. The numerical model should also consider the precise EC distribution to further improve the estimation of aerosol radiative forcing globally. Meanwhile, the measurement techniques of aerosol properties urgently need to improve, especially for the identification, size distribution, and refractive indices of EC, so that they could entered accurately into regional and global climate models. 


\section{Acknowledgements}

This study was sponsored in part by the National Science Foundation of China (NSFC) under Grant No. 41030962 and 41475142, the Priority Academic Program of Development of Jiangsu Higher Education Institutions (PAPD), and the Program for Postgraduates Research and Innovation in Universities of Jiangsu Province under Grant No. KYLX_0835 and No. KYLX15_0867. We would like to thank Dr. Yafang Cheng, Dr. Na Ma and Dr. Haobo Tan for helping us with the Mie code.

\section{References}

Anderson, T., Covert, D., Marshall, S., Laucks, M., Charlson, R., Waggoner, A., Ogren, J., Caldow, R., Holm, R., Quant, F., Sem, G., Wiedensohler, A., Ahlquist, N., Bates, T., 1996. Performance characteristics of a high-sensitivity, three-wavelength, total scatter/backscatter nephelometer. J. Atmos. Ocean. Technol. 13, 967-986.

Anderson, T., Ogren, J., 1998. Determining aerosol radiative properties using the TSI 3563 integrating nephelometer. Aerosol Sci. Technol. 29, 57-69.

Andreae, M., Gelencsér, A., 2006. Black carbon or brown carbon? The nature of light-absorbing carbonaceous aerosols. Atmos. Chem. Phys. 6, 3131-3148.

Andreae, M., Rosenfeld, D., 2008. Aerosol-cloud-precipitation interactions. Part 1. The nature and sources of cloud-active aerosols. Earth-Science Reviews 89, 13-41.

Barnard, J., Kassianov, E., Ackerman, T., Frey, S., Johnson, K., Zuberi, B., Molina, L., Molina, M., 2007. Estimation of a "radiatively correct" black carbon specific absorption during the Mexico City Metropolitan Area (MCMA) 2003 field campaign. Atmos. Chem. Phys. 7, 1645-1655.

Birmili, W., Stratmann, F., Wiedensohler, A., Covert, D, Russel, L., Berg, O., 1997. Determination of differential mobility analyzer transfer functions using identical instruments in series. Aerosol Sci. Technol. 27, 215-223.

Bohren, C., Huffman, D., 2008. Absorption and scattering of light by small particles. New York: John Wiley \& Sons Inc. 
Cappa, C., Onasch, T., Massoli, P., Worsnop, D., Bates, T., Cross, E., Davidovits, P., Hakala, J., Hayden, K., Jobson, B., Kolesar, K., Lack, D., Lerner, B., Li, S., Mellon, D., Nuaaman, I., Olfert, J., Petäjä, T., Quinn, P., Song, C., Subramanian, R., Williams, E., Zaveri, R., 2012. Radiative absorption enhancements due to the mixing state of atmospheric black carbon. Science 337, 1078-1081.

Chamaillard, K., Kleefeld, C., Jennings, S., Ceburnis, D., O’Dowd, C., 2006. Light scattering properties of sea-salt aerosol particles inferred from modeling studies and ground-based measurements. J. Quant. Spectrosc. Radiat. Transfer 101, 498-511.

Charlson, R., Schwartz, S., Hales, J., Cess, R., Coakley, J., Hansen, J., Hofmann, D., 1992. Climate forcing by anthropogenic aerosols. Science 255, 423-430.

Chen, K., Yin, Y., Kong, S., Xiao, H., Wu, Y., Chen, J., Li, A., 2014. Size-resolved chemical composition of atmospheric particles during a straw burning period at Mt. Huang (the Yellow Mountain) of China. Atmos. Environ. 84, 380-389.

Cheng, Y. F., Wiedensohler, A., Eichler, H., Su, H., Gnauk, T., Brüggemann, E., Herrmann, H., Heintzenberg, J., Slanina, J., Tuch, T., Hu, M., Zhang, Y. H., 2008. Aerosol optical properties and related chemical apportionment at Xinken in Pearl River Delta of China. Atmos. Environ. 2008, $42(25), 6351-6372$.

Cheng, Y., Eichler, H., Wiedensohler, A., Heintzenberg, J., Zhang, Y., Hu, M., Herrmann, H., Zeng, L., Liu, S., Gnauk, T., Brüggemann, E., He, L., 2006. Mixing state of elemental carbon and non-light-absorbing aerosol components derived from in situ particle optical properties at Xinken in Pearl River Delta of China. J. Geophys. Res. Atmos. 111, D20, doi: 10.1029/2005JD006929.

Chung, S., Seinfeld, J., 2002. Global distribution and climate forcing of carbonaceous aerosols. J. Geophys. Res. Atmos. 107, D19, AAC 14-1-AAC 14-33, doi:10.1029/2001JD001397.

Feng, Y., Ramanathan, V., Kotamarthi, V., 2013. Brown carbon: a significant atmospheric absorber of solar radiation?. Atmos. Chem. Phys. 13, 8607-8621.

Fuller, K., Malm, W., Kredenweis, S., 1999. Effects of mixing on extinction by carbonaceous particles. J. Geophys. Res. Atmos. 104, D13, 15941-15954, doi: 10.1029/1998JD100069.

Gu, X., 2013. Observational study of size-resolved aerosol activation and hygroscopic properties in South China. Ph.D. Thesis, Nanjing University of Information Science \& Technology. 
He, X., Li, C., Lau, A., Deng, Z., Mao, J., Wang, M., Liu, X., 2009. An intensive study of aerosol optical properties in Beijing urban area. Atmos. Chem. Phys. 9, 8903-8915.

Höller, R., Ito, K., Tohno, S., Kasahara, M., 2003. Wavelength-dependent aerosol single-scattering albedo: Measurements and model calculations for a coastal site near the Sea of Japan during ACE-Asia. J. Geophys. Res. Atmos. 108, D23, doi: 10.1029/2002JD003250.

Horvath, H., 1993. Atmospheric light absorption-A review. Atmos. Environ. Part A 27, 293-317.

IPCC, 2013. Climate change 2013: the physical science basis. New York: Cambridge University Press.

Jacobson, M. Z., 2001. Strong radiative heating due to the mixing state of black carbon in atmospheric aerosols. Nature 409, 695-697.

Jacobson, M., 2000. A physically-based treatment of elemental carbon optics: Implications for global direct forcing of aerosols. Geophys. Res. Lett. 27, 217-220.

Jeong, C., Evans, G., McGuire, M., Chang, R., Abbatt, J., Zeromskiene, K., Mozurkewich, M., Li, S., Leaitch, W., 2010. Particle formation and growth at five rural and urban sites. Atmos. Chem. Phys. 10, 7979-7995.

Kaaden, N., Massling, A., Schladitz, A., Muller, T., Kandler, K., Schutz, L., Weinzierl, B., Petzold, A., Tesche, M., Leinert, S., Deutscher, C., Ebert, M., Weinbruch, S., Wiedensohler, A., 2009. State of mixing, shape factor, number size distribution, and hygroscopic growth of the Saharan anthropogenic and mineral dust aerosol at Tinfou, Morocco. Tellus 61B, 51-63.

Kleefeld, C., O'Dowd, C., O'Reilly, S., Jennings, S., Aalto, P., Becker, E., Kunz, G., and de Leeuw, G., 2002. Relative contribution of submicron and supermicron particles to aerosol light scattering in the marine boundary layer. J. Geophys. Res. Atmos. 107, D19, doi: 10.1029/2000JD000262.

Kulkarni, P., Baron, P., Willeke, K., 2011. Aerosol measurement: principles, techniques, and applications. John Wiley \& Sons.

Li, L., Huang, Z., Dong, J., Li, M., Gao, W., Nian, H., Fu, Z., Zhang, G., Bi, X., Cheng, P., Zhou, Z., 2011. Real time bipolar time-of-flight mass spectrometer for analyzing single aerosol particles. Int. J. Mass spectrom. 303, 118-124.

Li, L., Yin, Y., Kong, S., Wen, B., Chen, K., Yuan, L., Li, Q., 2014. Altitudinal effect to the size distribution of water soluble inorganic ions in PM at Huangshan, China. Atmos. Environ. 98, 
$242-252$.

Liu C., Panetta, R., Yang, P., 2012. The influence of water coating on the optical scattering properties of fractal soot aggregates. Aerosol Sci. Tech. 46, 32-43.

Liu, C., Panetta, R., Yang, P., 2014. Inhomogeneity structure and the applicability of effective medium approximations in calculating light scattering by inhomogeneous particles. J. Quant. Spectrosc. Radiat. Transfer 146, 331-348.

Lu, Z., Streets, D., Winijkul, E., Yan, F., Chen, Y., Bond, T., Feng, Y., 2015. Dubey, M. K.; Liu, S.; Pinto, J. P.; Carmichael, G. R., Light Absorption Properties and Radiative Effects of Primary Organic Aerosol Emissions. Environ. Sci. Technol. 49, 4868-4877.

Ma, N., Zhao, C., Müller, T., Cheng, Y., Liu, P., Deng, Z., Xu, W., Ran, L., Nekat, B., van Pinxteren, D., Gnauk, T., Müller, K., Herrmann, H., Yan, P., Zhou, X., and Wiedensohler, A., 2012. A new method to determine the mixing state of light absorbing carbonaceous using the measured aerosol optical properties and number size distributions. Atmos. Chem. Phys. 12, $2381-2397$.

Ma, N., Zhao, C., Nowak, A., Müller, T., Pfeifer, S., Cheng, Y., Deng, Z., Liu, P., Xu, W., Ran, L., Yan, P., Göbel, T., Hallbauer, E., Mildenberger, K., Henning, S., Yu, J., Chen, L., Zhou, X., Stratmann, F., Wiedensohler, A., 2011. Aerosol optical properties in the North China Plain during HaChi campaign: an in-situ optical closure study. Atmos. Chem. Phys. 11, 5959-5973.

Magee Scientific, 2005. The Aethalometer ${ }^{\mathrm{TM}}$. Berkeley, CA: Magee Scientific Company.

Moffet, R., Prather, K., 2009. In-situ measurements of the mixing state and optical properties of soot with implications for radiative forcing estimates. PNAS 106 11872-11877, doi:10.1073/pnas.0900040106.

Moosmüller, H., Arnott, W., Rogers, C., Chow, J., Frazier, C., Sherman, L., Dietrich, D., 1998. Photoacoustic and filter measurements related to aerosol light absorption during the Northern Front Range Air Quality Study (Colorado 1996/1997). J. Geophys. Res. Atmos. 103, D21, 28149-28157, doi: 10.1029/98JD02618.

Murphy, D., Anderson, J., Quinn, P., McInnes, L., Brechtel, F., Kreidenweis, S., Middlebrook, A., Posfai, M., Thomson, D., and Buseck, P., 1998. Influence of sea-salt on aerosol radiative properties in the Southern Ocean marine boundary layer. Nature 392, 62-65.

Peters, T., Leith, D., 2003. Concentration measurement and counting efficiency of the 
aerodynamic particle sizer 3321. J. Aerosol Sci. 34, 627-634.

Riemer, N., Vogel, H.; Vogel, B., 2004. Soot aging time scales in polluted regions during day and night. Atmos. Chem. Phys. 4, 1885-1893.

Shen, X., 2012. Characteristics of the particle number size distribution and optical properties at Mt. Tai. Ph. D. Thesis, Institute of Atmospheric Physics, Chinese Academy of Sciences, Chinese Academy of Meteorological Sciences.

Stratmann, F., Wiedensohler, A., 1996. A new data inversion algorithm for DMPS-measurements. J. Aerosol Sci. 27, 339-340.

Valipour, M., 2015a. Investigation of Valiantzas' evapotranspiration equation in Iran. Theor. Appl. Climatol. 121, 267-278.

Valipour, M., 2015b. Evaluation of radiation methods to study potential evapotranspiration of 31 provinces. Meteorol. Atmos. Phys. 127, 289-303.

Valipour, M., 2015c. Comparative Evaluation of Radiation-Based Methods for Estimation of Potential Evapotranspiration. J. Hydrol. Eng. 20, 04014068, doi: 10.1061/(ASCE)HE.1943-5584.0001066.

Valipour, M., 2015d. Study of different climatic conditions to assess the role of solar radiation in reference crop evapotranspiration equations. Archives of Agronomy and Soil Science 61, 679-694.

Valipour, M., Eslamian, S., 2014. Analysis of potential evapotranspiration using 11 modified temperature-based models. Int. J. Hydrology Science and Technology 4, 192-207.

Wex, H., Neusüß, C., Wendisch, M., Stratmann, F., Koziar, C., Keil, A., Wiedensohler, A., Ebert, M., 2002. Particle scattering, backscattering, and absorption coefficients: An in situ closure and sensitivity study. J. Geophys. Res. Atmos. 107, D21, LAC 4-1-LAC 4-18, doi: 10.1029/2000JD000234.

Wiedensohler, A., Birmili, W., Nowak, A., Sonntag, A., Weinhold, K., Merkel, M., Wehner, B., Tuch, T., Pfeifer, S., Fiebig, M., Fjäraa, A., Asmi, E., Sellegri, K., Depuy, R., Venzac, H., Villani, P., Laj, P., Aalto, P., Ogren, J., Swietlicki, E., Williams, P., Roldin, P., Quincey, P., Hüglin, C., Fierz-Schmidhauser, R., Gysel, M., Weingartner, E., Riccobono, F., Santos, S., Grüning, C., Faloon, K., Beddows, D., Harrison, R., Monahan, C., Jennings, S., O'Dowd, C., Marinoni, A., Horn, H., Keck, L., Jiang, J., Scheckman, J., McMurry, P., Deng, Z., Zhao, C., Moerman, M., 
Henzing, B., de Leeuw, G., Löschau, G., Bastian, S., 2012. Mobility particle size spectrometers: harmonization of technical standards and data structure to facilitate high quality long-term observations of atmospheric particle number size distributions. Atmos. Meas. Tech. 5, 657-685.

Wiedensohler, A., Orsini, D., Covert, D., Coffmann, D., Cantrell, W., Havlicek, M., Brechtel, F., Russell, L., Weber, R., Gras, J., Hudson, J., Litchy, M., 1997. Intercomparision study of the sizedependent counting efficiency of 26 condensation particle counters. Aerosol Sci. Technol. $27,224-242$.

Wu, D., Mao, J., Deng, X., Tie, X., Zhang, Y., Zeng, L., Li, F., Tan, H., Bi, X., Huang, X., Chen, J., Deng, T., 2009. Black carbon aerosols and their radiative properties in the Pearl River Delta region. Sci. ChinaSer. D-Earth Sci. 52, 1152-1163.

Yan, P., Tang, J., Huang, J., Mao, J., Zhou, X., Liu, Q., Wang, Z., Zhou, H., 2008. The measurement of aerosol optical properties at a rural site in Northern China. Atmos. Chem. and Phys. 8, 2229-2242.

Yuan, L., Yin, Y., Yu, X., Xiao, H., Wen, B., 2013. Observational study of aerosol optical properties in summer in Mt. Huang. China Environ. Sci. 33, 1231-1239.

Zhuang, B., Wang T., Liu J., Ma, Y., Yin, C., Li, S., Xie, M., Han, Y., Zhu, J., Yang, X., Fu, C., 2015. Absorption coefficient of urban aerosol in Nanjing, west Yangtze River Delta, China. Atmos. Chem. Phys. Discuss. 15, 13633-13646.

Zhuang, B., Wang, T., Liu, J., Li, S., Xie, M., Yang, X., Fu, C., Sun, J., Yin, C., Liao, J., Zhu, J., Zhang, Y., 2014. Continuous measurement of black carbon aerosol in urban Nanjing of Yangtze River Delta, China. Atmos. Environ. 89, 415-424. 